\title{
CONDIÇÕES HIGIÊNICO-SANITÁRIAS DE MÁQUINAS DE MOER CARNE, MÃOS DE MÁNIPULADORES E QUALIDADE MICROBIOLÓGICA DA CARNE MOÍDA
}

\author{
Hygienic-sanitary conditions of meat-grinding machines, \\ handlers' hands and microbiologic quality of ground meat \\ Maíra Maciel Mattos de Oliveira ${ }^{1}$, Danilo Florisvaldo Brugnera ${ }^{2}$, \\ Alexandre Tourino Mendonça ${ }^{3}$, Roberta Hilsdorf Piccoli ${ }^{4}$
}

\begin{abstract}
RESUMO
Foram avaliadas condições higiênico-sanitárias de máquinas de moer carne e mãos de manipuladores e observou-se a interferência na qualidade microbiológica da carne moída. Nas máquinas de moer carne e mãos de manipuladores, realizaram-se análises de microrganismos aeróbios mesófilos, fungos filamentosos e leveduras, coliformes totais e termotolerantes, Escherichia coli e estafilococos coagulase positiva. Nenhuma das máquinas enquadrou-se nos padrões da APHA. Para manipuladores, as contagens de aeróbios mesófilos, estafilococos coagulase positiva, fungos filamentosos e leveduras, coliformes totais e termotolerantes apresentaram-se elevadas. Nas amostras de carne inteira e moída, realizaram-se, além das citadas acima, análises de Salmonella sp. aeróbios psicrotróficos e clostrídios sulfito-redutores. Comparando-se os resultados das análises microbiológicas das carnes antes e após a moagem e manipulação, constatou-se aumento da contagem microbiana na maioria das amostras analisadas, indicando higienização inadequada das máquinas de moer e mão dos manipuladores.
\end{abstract}

Termos para indexação: Contaminação cruzada, carne moída, análise microbiológica.

\begin{abstract}
Hygienic-sanitary conditions of meat grinding-machines and handlers' hands were evaluated and the interference on the microbiologic quality of the ground meat was observed. In the meat-ground machines and handlers' hands analyses of mesophyllic aerobic microorganisms, filamentous fungi and yeasts, total and heat-tolerant coliforms, Escherichia coli and positive coagulase staphylococcus were accomplished. None of the machines fitted in the APHA standards. For the handlers, the counts of mesophyllic aerobes, positive coagulase staphylococcus, filamentous fungi and yeasts, total and heat-tolerant coliforms proved elevated. In the samples of whole and ground meat, in addition to those above-cited, analyses of Salmonella sp. psychotrophic aerobes and sulfite-reducing clostridia were performed. By comparing the results of the microbiological analyses of the meats before and after grinding and handling, an increase of the microbial count in most of the samples analyzed was found, denoting inadequate cleaning of the grinding-machines and handlers' hands.
\end{abstract}

Index terms: Cross contamination, ground meat, microbiologic analysis.

(Recebido em 3 de abril de 2006 e aprovado em 31 de outubro de 2006)

\section{INTRODUÇÃo}

A carne na forma moída é amplamente utilizada hoje em dia, pela versatilidade de pratos que permite elaborar. De acordo com Martinelli Filho et al. (1975) a carne moída constitui um meio altamente favorável para multiplicação de bactérias, sendo a fragmentação dos tecidos responsáveis pela liberação de suco celular, propiciando a proliferação das mesmas no produto.

Existem diversas fontes de contaminação da carne, dentre elas destacam-se: a deficiência no controle da higiene durante o abate do animal, tempo e temperatura de estocagem nos pontos de venda e varejo, higienização dos equipamentos e excesso de manipulação (MARQUES, 1991).

Os manipuladores representam um dos principais veículos de contaminação da carne, uma vez que sua participação chega a atingir até $26 \%$ dos surtos de toxinfecção alimentar (ANDRADE \& BRABES, 2003). Já a contaminação proveniente dos equipamentos de moagem ou cutters, apesar de algumas vezes citada, ainda não foi analisada laboratorialmente (MARQUES, 1991). Contudo, Hazelwood \& Mclean (1994), relata que se qualquer peça do equipamento for de difícil limpeza, esterilização ou sanificação, é mais do que provável que essas tarefas essenciais não serão

\footnotetext{
Zootecnista, Mestranda em Ciência dos Alimentos - Departamento de Ciência dos Alimentos/DCA - Universidade Federal de Lavras/UFLA - Cx. P. 3037 - 37200-000 - Lavras, MG - mmacielmattos@yahoo.com.br

${ }^{2}$ Graduando em Zootecnia - Departamento de Ciência dos Alimentos/DCA - Universidade Federal de Lavras/UFLA - Cx. P. 3037 - 37200-000 - Lavras, $\mathrm{MG}$-danilobrugnera@hotmail.com

${ }^{3}$ Zootecnista, Doutor em Ciência dos Alimentos, Professor Titular - Universidade Vale do Rio Verde/UNINCOR - Rua Castelo Branco, 82 - Chácara das Rosas - 37410-000 - Três Corações, MG - tourinounincor@yahoo.com.br

${ }^{4}$ Engenheira de Alimentos, Doutora em Ciência e Tecnologia de Alimentos, Professora Adjunto - Departamento de Ciência dos Alimentos/DCA Universidade Federal de Lavras/UFLA - Cx. P. 3037 - 37200-000 - Lavras, MG - rhpiccoli@ufla.br
} 
realizadas a contento, havendo acúmulo de restos de alimentos e bactérias patogênicas ou deterioradoras, aumentando assim os riscos de contaminação cruzada em toda a área destinada ao processamento.

A forma mais usual para comprovar as condições de higiene dos ambientes, equipamentos, utensílios, e manipuladores consiste em inspecioná-los quanto à contaminação microbiológica, após serem submetidos ao processo de higienização. Sabe-se que a limpeza aparente pode induzir a erros e dar falsa sensação de segurança (SIQUEIRA JÚNIOR et al., 2004).

Neste trabalho, foram avaliadas as condições higiênico-sanitárias de máquinas de moer carne e mãos de manipuladores e observada a interferência na qualidade microbiológica da carne moída pela análise da mesma, inteira e após a manipulação e moagem.

\section{MATERIALE MÉTODOS}

As análises microbiológicas foram realizadas no laboratório de Microbiologia de Alimentos do Departamento de Ciência dos Alimentos da Universidade Federal de Lavras.

Foram avaliados cinco estabelecimentos comerciais do município de Lavras, realizando-se três repetições em duplicata. Todas as análises microbiológicas foram feitas de acordo com Silva et al. (2001).

Na carne em pedaço, moída, mãos de manipuladores e máquinas de moer foram quantificados microrganismos aeróbios mesófilos, aeróbios psicrotróficos, fungos filamentosos e leveduras, estafilococos coagulase positiva, coliformes totais e termotolerantes e presença de Escherichia coli. Salmonella sp. e clostrídios sulfito-redutores foram pesquisados apenas na carne em pedaço e na carne moída.

\section{Avaliação microbiológica da carne em pedaço e da carne moída}

Para avaliação microbiológica da carne, foram adquiridas, nos estabelecimentos, porções de $100 \mathrm{~g}$ de patinho, sendo $50 \mathrm{~g}$ da carne moída na hora e o restante embalado separadamente em pedaços inteiros. A máquina de moer carne utilizada em cada estabelecimento foi previamente higienizada pelos manipuladores de forma rotineira, sem interferência no processo.

\section{Avaliação microbiológica da palma das mãos dos manipuladores}

Cinco manipuladores, um de cada estabelecimento comercial, tiveram a superfície da palma de suas mãos avaliadas microbiologicamente. Todos os manipuladores escolhidos eram responsáveis pelo funcionamento da máquina de moer carne no seu respectivo estabelecimento comercial.
Swabs foram usados para a amostragem das palmas das mãos dos manipuladores consideradas higienizadas. A amostragem da superfície da palma da mão dos manipuladores foi realizada de acordo com a técnica descrita pela APHA (American Public Health Association) (SVEUM et al., 2002).

Após a amostragem, os swabs foram dispensados em tubos contendo $10 \mathrm{~mL}$ de água peptonada $(0,1 \%)$, e procederam-se as análises microbiológicas.

\section{Avaliação microbiológica da máquina de moer carne}

Em cada um dos cinco estabelecimentos comerciais, foi submetida à avaliação microbiológica uma máquina de moer carne, utilizando-se a técnica de esfregaço de superfície empregando-se $S w a b s$ e seguindo-se as recomendações de APHA (SVEUM et al., 1992). Os Swabs foram passados em área correspondente a $100 \mathrm{~cm}^{2}$ da boca da máquina de moer.

Após a amostragem, os swabs foram dispensados em tubos contendo $10 \mathrm{~mL}$ de água peptonada, e procederam-se as análises microbiológicas.

\section{Análises microbiológicas}

Utilizou-se Ágar Padrão para Contagem (PCA) para análise de microrganismos aeróbios mesófilos e psicrotróficos e Batata Dextrose Ágar (BDA) acidificado com ácido tartárico a $10 \%$ para a análise de fungos filamentosos e leveduras.

Como teste presuntivo para coliformes totais utilizou-se o Caldo Lauril Sulfato Triptose (LST) como teste confirmativo de coliformes totais o Caldo Bile Verde Brilhante (VB) e o Caldo Escherichia coli (EC) como teste confirmativo de coliformes termotolerantes. A confirmação da presença de Escherichia coli foi realizada utilizando-se o Ágar Eosina Azul de Metileno (EMB), coloração de Gram e as provas bioquímicas de Indol, Vermelho de Metila, Voges Proskauer e Citrato (IMVC).

Para detectar a presença de estafilococos coagulase positiva, utilizou-se o Ágar Baird-Parker (BP). Colônias suspeitas foram submetidas ao teste de produção de coagulase, sendo as culturas submetidas à coloração de Gram e provas adicionais de catalase e termonuclease.

Utilizou-se, para avaliação de Salmonella, como pré-enriquecimento, Água Peptonada Tamponada e, como enriquecimento, os Caldos Tetrationato (TT) e Rappaport (RR) e Ágar Rambach para isolamento. Colônias suspeitas foram estriadas em tubos contendo Ágar Ferro Trípice Açúcar (TSI) e Ágar Lisina Ferro (LIA). Os tubos de TSI e LIA que apresentaram reações típicas de Salmonella foram submetidas a testes bioquímicos iniciais de urease, fermentação do dulcitol, indol e malonato.

Para a análise de clostrídios sulfito-redutores utilizouse o Ágar Triptose Sulfito Cicloserina (TSC) com adição de sobrecamada e incubação sob anaerobiose a $46^{\circ} \mathrm{C} / 24 \mathrm{~h}$. 


\section{RESULTADOS E DISCUSSÕES}

No Quadro 1, estão expressos os resultados de UFC/g de microrganismos aeróbios mesófilos e aeróbios psicrotróficos, fungos filamentosos e leveduras, estafilococos coagulase positiva, NMP/g de coliformes totais, termotolerantes e Escherichia coli encontrados nas carnes em pedaço.

Excetuando o estabelecimento 1, todos os outros tiveram o número de microrganismos aeróbios mesófilos acima de $10^{4} \mathrm{UFC} / \mathrm{g}$. A contagem de psicrotróficos não se manteve acima de $10^{6} \mathrm{UFC} / \mathrm{g}$ no estabelecimento 3 , que, de acordo com a Tabela 1, apresentou contagem de 2,84 x 10 UFC/g. Esses resultados mostram a pouca higiene de obtenção e manipulação da carne. Sabe-se que é praticamente impossível obter contagens iguais a zero de microrganismos aeróbios mesófilos e psicrotróficos, tanto que, em produtos considerados frescos, não se exige padrão para estes grupos de microrganismos. De acordo com Leitão (2003) e Roça \& Serrano (1995), a deterioração inicia-se na carne com contagens na faixa de $10^{6} \mathrm{UFC} / \mathrm{g}$ de aeróbios mesófilos, sendo sucedida por odores estranhos $\left(10^{7}\right.$ a $\left.10^{9} \mathrm{UFC} / \mathrm{g}\right)$, alterações no sabor $\left(10^{8}\right.$ a $\left.10^{9} \mathrm{UFC} / \mathrm{g}\right)$ e na limosidade superficial $\left(10^{9} \mathrm{UFC} / \mathrm{g}\right)$. Aldelaimy \& Styles (1975) afirmam que com contagens iniciais de $10^{4}$ a $10^{5}$ UFC/g o período de conservação do produto pode atingir 3 a 4 dias quando estocado a $5^{\circ} \mathrm{C}$.

Assim, os resultados mostram que no patinho obtido nesses estabelecimentos, considerando o número de microrganismos aeróbios mesófilos encontrados, de acordo com os valores apresentados por Greer, citado por Leitão (2003), apenas o estabelecimento 5 apresentou as amostras próximas à deterioração $\left(4,2 \times 10^{6} \mathrm{UFC} / \mathrm{g}\right)$. Com relação aos psicrotróficos, somente o estabelecimento 3 apresentou contagem inferior a $10^{6} \mathrm{UFC} / \mathrm{g}$. Sabe-se que a temperatura de refrigeração varia de 0 a $7^{\circ} \mathrm{C}$. Contudo, um refrigerador doméstico, em razão de constantes aberturas, pode alcançar a temperatura de $14^{\circ} \mathrm{C}$, principalmente quando sua capacidade máxima está sendo utilizada (comunicação pessoal). Apesar de se prever na literatura a vida de prateleira de 3 a 5 dias, quando exposta a variações de temperatura a microbiota da carne aumentará mais rapidamente diminuindo sua vida útil.

As contagens de fungos filamentosos e leveduriformes foram superiores a $10^{4} \mathrm{UFC} / \mathrm{g}$ em $60 \%$ das amostras. Silva et al. (2004) coloca que valores elevados desses microrganismos podem causar toxinfecções decorrentes da ingestão de cepas patogênicas ou de seus metabólitos. Além disso, contagens representativas de fungos filamentosos e leveduriformes podem acelerar a deterioração dos alimentos em conseqüência de suas mais variadas enzimas produzidas.

Sendo detectada em 3 estabelecimentos, a presença de estafilococos coagulase positiva na carne é indesejada. Estafilococos coagulase positiva são microrganismos utilizados como indicadores de manipulação inadequada. Aproximadamente $20 \%$ dos indivíduos são colonizados por um tipo de cepa de $S$. aureus enquanto que $60 \%$ abrigam S. aureus com frequiência variada (SILVA \& GRANDA, 2004).

As análises de fungos filamentosos e leveduras, coliformes totais e termotolerantes, Escherichia coli e estafilococos coagulase positiva possuem ausência de padrões. Portanto, foram realizadas somente como indicativo de higiene.

As análises de clostrídios sulfito-redutores foram realizadas em razão da sua elevada incidência em carnes cruas e por se tratar de um microrganismo patogênico, constatando-se sua ausência em todas as amostras analisadas.

O padrão microbiológico adotado no Brasil para carne e produtos cárneos resfriados ou congelados "in natura”, carne moída e carnes preparadas cruas congeladas

Quadro 1 - Resultados de UFC/g de aeróbios mesófilos e psicrotróficos, fungos filamentosos e leveduras e estafilococos coagulase positiva, NMP/g de coliformes totais, termotolerantes e Escherichia coli, obtidos nas carnes inteiras dos cinco estabelecimentos comerciais analisados.

\begin{tabular}{cccccccc}
\hline $\mathrm{E}^{1}$ & $\mathrm{AM}^{2}$ & $\mathrm{AP}^{3}$ & $\mathrm{FFL}^{4}$ & $\mathrm{ECP}^{5}$ & $\mathrm{CT}^{6}$ & $\mathrm{CTE}^{7}$ & $\mathrm{EC}^{8}$ \\
\hline 1 & $3,00 \times 10^{1}$ & $1,65 \times 10^{6}$ & $1,44 \times 10^{5}$ & $1,40 \times 10^{3}$ & $0,23 \times 10^{1}$ & $0,15 \times 10^{1}$ & ausência \\
2 & $6,55 \times 10^{5}$ & $3,10 \times 10^{6}$ & $<10$ & $<10$ & $7,5 \times 10^{1}$ & $2,4 \times 10^{1}$ & ausência \\
3 & $2,75 \times 10^{5}$ & $2,84 \times 10^{5}$ & $7,35 \times 10^{3}$ & $<10$ & $0,09 \times 10^{1}$ & $0,03 \times 10^{1}$ & ausência \\
4 & $7,9 \times 10^{4}$ & $1,48 \times 10^{6}$ & $2,47 \times 10^{4}$ & $2,7 \times 10^{4}$ & $4,6 \times 10^{2}$ & $4,3 \times 10^{1}$ & ausência \\
5 & $4,2 \times 10^{6}$ & $2,56 \times 10^{6}$ & $2,74 \times 10^{4}$ & $1,8 \times 10^{4}$ & $1,1 \times 10^{2}$ & $0,23 \times 10^{1}$ & ausência \\
\hline
\end{tabular}

Dados referentes às medias obtidas das 3 repetições $\left({ }^{1}\right.$ estabelecimentos, ${ }^{2}$ aeróbios mesófilos, ${ }^{3}$ aeróbios psicrotróficos, ${ }^{4}$ fungos filamentosos e leveduras, ${ }^{5}$ estafilococos coagulase positiva, ${ }^{6}$ coliformes totais, ${ }^{7}$ coliformes termotolerantes, ${ }^{8}$ Escherichia coli) 
ou não, como bifes e outros, de acordo com a RESOLUÇÃO - RDC Nº12, DE 2 DE JANEIRO DE 2001 exige ausência de Salmonella sp., em $25 \mathrm{~g}$. Todas as amostras analisadas apresentaram-se isentas de contaminação por Salmonella sp., estando dentro dos padrões da legislação vigente.

No Quadro 2 estão expressos os resultados de UFC/ $\mathrm{cm}^{2}$ de mesófilos aeróbios, fungos filamentosos e leveduras e estafilococos coagulase positiva, $\mathrm{NMP} / \mathrm{cm}^{2}$ de coliformes totais, termotolerantes e Escherichia coli encontrados nas máquinas de moer carne.

Para superfícies de equipamentos e utensílios a APHA recomenda o máximo de $2 \mathrm{UFC} / \mathrm{cm}^{2}$ e a Organização Mundial de Saúde (OMS) o limite máximo de cerca de $50 \mathrm{UFC} / \mathrm{cm}^{2}$. Niskanen \& Pohja (1977) consideram um nível bom menos que $10 \mathrm{UFC} / \mathrm{cm}^{2}$, satisfatório entre 10 e $20 \mathrm{UFC} / \mathrm{cm}^{2}$, insatisfatório maior que $20 \mathrm{UFC} / \mathrm{cm}^{2}$. Já Solberg et al. (1977) consideram aceitável até $20 \mathrm{UFC} / 1,8 \mathrm{~cm}^{2}$, preocupante entre 20 e $40 \mathrm{UFC} / 1,8 \mathrm{~cm}^{2}$ e perigoso maior que $40 \mathrm{UFC} / 1,8 \mathrm{~cm}^{2}$.

Nenhuma das máquinas de moer carne enquadrouse nas especificações microbiológicas citadas acima, sendo considerada a possibilidade de formação de biofilmes bacterianos. Para se considerar um biofilme, segundo Andrade et al. (1998) é necessário um número mínimo de $10^{7}$ células aderidas por $\mathrm{cm}^{2}$.
Pelo quadro 3, verifica-se a concentração de microrganismos aeróbios mesófilos, fungos filamentosos e leveduras, estafilococos coagulase positiva, coliformes totais e termotolerantes e presença ou ausência de Escherichia coli na carne moída oriunda dos 5 estabelecimentos.

A microbiota presente na carne moída depende de vários fatores, dentre eles da qualidade da matéria prima e condições higiênicas do processamento (CAMARGO et al., 1981).

Dentre os gêneros bacterianos mais comumente encontrados na carne moída estão: Escherichia, Salmonella, Clostridium e Staphylococcus além de fungos filamentosos e leveduriformes (FRAZIER \& WESTHOFF, 1993).

De modo geral, o número de microrganismos aeróbios mesófilos, psicrotróficos e estafilococos coagulase positiva aumentou em relação à carne em pedaço. Esse fato deve ser reflexo da elevada contaminação das máquinas de moer carne (Quadro 2) uma vez que a carne ao ser moída entra em íntimo contato com a máquina. As mãos dos manipuladores também podem ter sido fonte de contaminação da carne.

No Quadro 4, observa-se a concentração de microrganismos aeróbios mesófilos, fungos filamentosos

Quadro 2 - Resultados de UFC/ $\mathrm{cm}^{2}$ de aeróbios mesófilos, fungos filamentosos e leveduras e estafilococos coagulase positiva, $\mathrm{NMP} / \mathrm{cm}^{2}$ de coliformes totais, termotolerantes e Escherichia coli, obtidos nas máquinas de moer dos cinco estabelecimentos comerciais analisados.

\begin{tabular}{ccccccc}
\hline $\mathrm{E}^{1}$ & $\mathrm{AM}^{2}$ & $\mathrm{FFL}^{3}$ & $\mathrm{ECP}^{4}$ & $\mathrm{CT}^{5}$ & $\mathrm{CTE}^{6}$ & $\mathrm{EC}^{7}$ \\
\hline 1 & $5,05 \times 10^{5}$ & $3,00 \times 10^{2}$ & $2,90 \times 10^{2}$ & $2,40 \times 10^{2}$ & $0,21 \times 10^{1}$ & ausência \\
2 & $2,62 \times 10^{4}$ & $2,56 \times 10^{3}$ & $2,60 \times 10^{3}$ & $1,10 \times 10^{2}$ & $4,60 \times 10^{1}$ & $0,30 \times 10^{1}$ \\
3 & $2,60 \times 10^{5}$ & $5,05 \times 10^{3}$ & $8,50 \times 10^{3}$ & $4,30 \times 10^{1}$ & $2,30 \times 10^{1}$ & ausência \\
4 & $9,60 \times 10^{4}$ & $3,95 \times 10^{3}$ & $3,10 \times 10^{3}$ & $0,43 \times 10^{1}$ & $0,40 \times 10^{1}$ & ausência \\
5 & $3,70 \times 10^{5}$ & $1,02 \times 10^{4}$ & $2,00 \times 10^{4}$ & $1,10 \times 10^{2}$ & $2,10 \times 10^{1}$ & $0,23 \times 10^{1}$ \\
\hline
\end{tabular}

Dados referentes às medias obtidas das 3 repetições $\left({ }^{1}\right.$ estabelecimentos, ${ }^{2}$ aeróbios mesófilos, ${ }^{3}$ fungos filamentosos e leveduras, ${ }^{4}$ estafilococos coagulase positiva, ${ }^{5}$ coliformes totais, ${ }^{6}$ coliformes termotolerantes, ${ }^{7}$ Escherichia coli)

Quadro 3 - Resultados de UFC/g de aeróbios mesófilos e psicrotróficos, fungos filamentosos e leveduras e estafilococos coagulase positiva, NMP/g de coliformes totais, termotolerantes e Escherichia coli, obtidos nas carnes moídas dos cinco estabelecimentos comerciais analisados.

\begin{tabular}{cccccccc}
\hline $\mathrm{E}^{1}$ & $\mathrm{AM}^{2}$ & $\mathrm{AP}^{3}$ & $\mathrm{FFL}^{4}$ & $\mathrm{ECP}^{5}$ & $\mathrm{CT}^{6}$ & $\mathrm{CTE}^{7}$ & $\mathrm{EC}^{8}$ \\
\hline 1 & $5,20 \times 10^{1}$ & $5,75 \times 10^{7}$ & $9,25 \times 10^{5}$ & $3,50 \times 10^{3}$ & $2,40 \times 10^{4}$ & $0,23 \times 10^{1}$ & ausência \\
2 & $2,65 \times 10^{6}$ & $2,03 \times 10^{7}$ & $1,06 \times 10^{5}$ & $3,30 \times 10^{3}$ & $1,50 \times 10^{1}$ & $0,43 \times 10^{1}$ & $0,23 \times 10^{1}$ \\
3 & $2,95 \times 10^{5}$ & $3,35 \times 10^{5}$ & $4,85 \times 10^{3}$ & $1,40 \times 10^{4}$ & $0,90 \times 10^{1}$ & $0,30 \times 10^{1}$ & ausência \\
4 & $8,3 \times 10^{5}$ & $7,15 \times 10^{6}$ & $2,35 \times 10^{4}$ & $1,10 \times 10^{5}$ & $2,40 \times 10^{1}$ & $0,15 \times 10^{1}$ & $4,00 \times 10^{1}$ \\
5 & $4,00 \times 10^{6}$ & $4,00 \times 10^{5}$ & $1,39 \times 10^{4}$ & $7,50 \times 10^{4}$ & $1,1 \times 10^{4}$ & $0,40 \times 10^{1}$ & ausência \\
\hline
\end{tabular}

Dados referentes às medias obtidas das 3 repetições ( ${ }^{1}$ estabelecimentos, ${ }^{2}$ aeróbios mesófilos, ${ }^{3}$ aeróbios psicrotróficos, ${ }^{4}$ fungos filamentosos e leveduras, ${ }^{5}$ estafilococos coagulase positiva, ${ }^{6}$ coliformes totais, ${ }^{7}$ coliformes termotolerantes, ${ }^{8}$ Escherichia coli) 
Quadro 4 - Resultados de UFC/mão de aeróbios mesófilos, fungos filamentosos e leveduras e estafilococos coagulase positiva, NMP/mão de coliformes totais, termotolerantes e Escherichia coli, obtidos nas mãos de manipuladores dos cinco estabelecimentos comerciais analisados.

\begin{tabular}{ccccccc}
\hline $\mathrm{E}^{1}$ & $\mathrm{AM}^{2}$ & $\mathrm{FFL}^{3}$ & $\mathrm{ECP}^{4}$ & $\mathrm{CT}^{5}$ & $\mathrm{CTE}^{6}$ & $\mathrm{EC}^{7}$ \\
\hline 1 & $2,90 \times 10^{5}$ & $2,00 \times 10^{4}$ & $2,60 \times 10^{3}$ & $4,60 \times 10^{1}$ & $4,60 \times 10^{1}$ & ausência \\
2 & $5,85 \times 10^{6}$ & $1,03 \times 10^{3}$ & $6,20 \times 10^{4}$ & $4,60 \times 10^{3}$ & $4,60 \times 10^{3}$ & ausência \\
3 & $9,35 \times 10^{4}$ & $7,85 \times 10^{4}$ & $3,10 \times 10^{4}$ & $4,30 \times 10^{1}$ & $1,50 \times 10^{1}$ & ausência \\
4 & $2,80 \times 10^{4}$ & $1,75 \times 10^{7}$ & $5,80 \times 10^{3}$ & $0,43 \times 10^{1}$ & $0,43 \times 10^{1}$ & ausência \\
5 & $3,60 \times 10^{5}$ & $3,95 \times 10^{3}$ & $1,40 \times 10^{5}$ & $4,60 \times 10^{1}$ & $0,90 \times 10^{1}$ & ausência \\
\hline
\end{tabular}

Dados referentes às medias obtidas das 3 repetições $\left({ }^{1}\right.$ estabelecimentos, ${ }^{2}$ aeróbios mesófilos, ${ }^{3}$ fungos filamentosos e leveduras, ${ }^{4}$ estafilococos coagulase positiva, ${ }^{5}$ coliformes totais, ${ }^{6}$ coliformes termotolerantes, ${ }^{7}$ Escherichia coli)

e leveduras, estafilococos coagulase positiva, coliformes totais e termotolerantes e presença ou ausência de Escherichia coli na mão de manipuladores dos 5 estabelecimentos comerciais.

Os manipuladores de carnes dos estabelecimentos estudados também se mostraram contaminados com elevadas concentrações de microrganismos aeróbios mesófilos e estafilococos coagulase positiva (Quadro 4 ). A presença de microrganismos mesófilos nas mãos dos manipuladores variou de 2,8 x $10^{4}$ a 5,85 x $10^{6}$ UFC/mão. Esses valores podem estar elevados pelo contato íntimo das mãos dos manipuladores com a carne que já pode ter vindo, dos fornecedores, contaminada (Quadro 1 ). Resultados microbiológicos satisfatórios para higiene das mãos são ausência de coliformes termotolerantes, estafilococos coagulase positiva, dentre outros (SILVA JUNIOR, 2001). Observando os resultados das análises da quantificação daqueles microrganismos conclui-se que as mãos dos cinco manipuladores se encontravam contaminadas uma vez que os números de estafilococos coagulase positiva variou de $2,6 \times 10^{3}$ a 1,4 x $10^{5} \mathrm{UFC} /$ mão e coliformes termotolerantes de $1,5 \times 10$ a $4,6 \times 10^{3}$. Segundo Silva Junior (2001) para que as mãos dos manipuladores sejam consideradas limpas, essas devem ser higienizadas a cada 1 hora, o que não ocorre nos estabelecimentos. A literatura brasileira vem demonstrando que o perfil higiênico-sanitário dos manipuladores de alimentos tem se mostrado, muitas vezes, inaceitável quanto à contaminação microbiana encontrada em diversos sítios anatômicos. Microrganismos como estafilococos coagulase positiva, coliformes termotolerantes e aeróbios mesófilos têm sido freqüentemente isolados das mãos dos manipuladores de alimentos (OLIVEIRA et al., 2003).

\section{CONCLUSÃO}

Os resultados das análises microbiológicas realizadas nos cinco estabelecimentos comerciais indicaram higienização inadequada das máquinas de moer e mão dos manipuladores, o que estaria sendo responsável pelo significativo aumento da contagem de microrganismos deteriorantes e patogênicos na maioria das amostras das carnes após a moagem e manipulação, encontrando-se muitas vezes impróprias para o consumo humano.

\section{REFERÊNCIAS BIBLIOGRÁFICAS}

ALDELAMY, K. S.; STYLES, M. E. Microbial quality and shelf life of raw ground beef. Canadian Journal of Public Health, Ottawa, v. 66, n. 4, p. 317-31, Apr. 1975.

ANDRADE, N. J.; BRABES, K. C. da S. Procedimentos de higienização e biofilmes microbianos na indústria de alimentos. In: MENDONÇA, R. C. S.; BRABES, K. C. da S.; OLIVEIRA, K. A. M.; VIEIRA, E. N. R. (Orgs.). Microbiologia de alimentos: qualidade e segurança na produção e consumo. Viçosa: Tribuna, 2003. v. 1, p. 145-160.

ANDRADE, N. J.; BRIDGEMAN, T. A.; ZOTTOLA, E. A. Bacteriocidal activity of sanitizers against Enterococcus faecium attached to stainless steel as determined by plate count and impedance methods. Journal of Food Protection, Des Moines, v. 61, n. 7, p. 833-838, 1998.

CAMARGO, M. R.; GRANER, M.; MARQUES FILHO, A. Qualidade microbiológica da carne bovina moída a nível de varejo e sua avaliação pela prova de resaurina. Revista de Microbiologia, São Paulo, v. 12, n. 1, p. 2227, 1981.

FRAZIER, W. C.; WESTHOFF, D. C. Microbiologia de los alimentos. 3. ed. Zaragaza: Acribia, 1993. 681 p. 
HALZELWOOD, H. D.; MCLEAN. Manual de higiene para manipuladores de alimentos. São Paulo: Varela, 1994. 140 p.

LEITÃO, M. F. F. Aspectos microbiológicos da carne. In: CASTILLO, C.; BROMBERG, R.; CIPOLLI, K. M. V. A. B.; MIYAGUSKU, L. Higiene e sanitização na indústria de carnes e derivados. São Paulo: Varela, 2003. 191 p.

MARQUES, K. P. S. Efeito da moagem no isolamento de Yersinia enterocolitica em carne bovina. 1991. $70 \mathrm{f}$. Dissertação (Mestrado em Ciência dos Alimentos) - Escola Superior de Agricultura “Luiz de Queiroz", Piracicaba, 1991.

MARTINELLI FILHO, A. M.; GRANER, M.; CRUZ, V. F. Microbiologia da carne moída: 3. avaliação da qualidade em diferentes épocas do ano. Anais da Escola Superior de Agricultura “Luiz de Queiroz", Piracicaba, v. 32, n. 1, jan./dez. 1975.

NISKANEN, A.; POHJA, M. S. Comparative studies on the sampling and investigation of microbial contaminations of surfaces by the contact plate and swab methods. Journal of Applied Bacteriology, Oxford, v. 42, p. 53-63, 1977.

OLIVEIRA, K. A. M.; VIEIRA, E. N. R. Microbiologia de alimentos: qualidade e segurança na produção e consumo. Viçosa: UFV, 2003.

ROÇA, R. U.; SERRANO, A. M. Abate de bovinos: alterações microbianas da carcaça. Higiene Alimentar, São Paulo, v. 9, n. 35, p. 8-13, 1995.
SILVA, C. A.; SOUSA, E. L.; SOUSA, C. P. Estudo da qualidade sanitária da carne moída comercializada na cidade de João Pessoa, PB. Revista Higiene Alimentar, São Paulo, v. 18, n. 121, p. 90-94, 2004.

SILVA JUNIOR, E. S. Manual de controle higiênicosanitário em alimentos. 4. ed. São Paulo: Varela, 2001.

SILVA, N.; JUNQUEIRA, V. C. A.; SILVEIRA, N. F. A.Manual de métodos de análise microbiológica de alimentos. 2. ed. São Paulo: Varela, 2001. 317 p.

SILVA, W. P.; GANDRA, E. A. Estafilococos coagulase positiva: patógenos de importância em alimentos. Revista Higiene Alimentar, São Paulo, v. 18, n. 122, 2004.

SIQUEIRA JÚNIOR, W. M.; CARELI, R. T.; ANDRADE, N. J.; MENDONÇA, R. C. S. Qualidade microbiológica de equipamentos, utensílios e manipuladores de uma indústria de processamento de carnes. Revista Nacional da Carne, São Paulo, ano 28, n. 326, p. 36-46, abr. 2004.

SOLBERG, M.; MISKIMIN, D. K.; MARTIN, B. A.; PAGE, G.; GOLCHAER, S.; LIBFIELD, M. Indicator organisms, food-borne pathogens and food safety. Association of Food and Drugs Officials, Washington, v. 41, n. 9, p. 21, 1977.

SVEUM, W. H.; MOBERG, L. J.; RUDE, R. A.; FRANK, J. F. Microbiological monitoring of the food processing environment. In: VANDERZANT, C.; SPLITTSTOESSER, D. F. (Eds.). Compendium of methods for the microbiological examination of foods. 3. ed. Washington, DC: APHA, 1992. p. 51-74. 